\title{
Pleural mesothelioma in a lift mechanic
}

\author{
M HUNCHAREK, ${ }^{14}$ J MUSCAT ${ }^{24}$ J CAPOTORTO $^{3}$ \\ From the Boston University School of Medicine Boston, ${ }^{1}$ Boston, Mass, Memorial Sloan-Kettering Cancer \\ Center, ${ }^{2}$ New York, Staten Island Hospital, ${ }^{3}$ Staten Island, New York, and Epidemiology Associates, ${ }^{4}$ Boston, \\ Mass, USA
}

The association of pleural mesothelioma with occupational exposure to asbestos is well documented. In the past, mesothelioma was observed primarily among miners, millers, and workers in the asbestos manufacturing industries. ${ }^{1}$ Subsequently, occupational groups using asbestos products such as insulators, pipe fitters, and shipyard and brake repair workers experienced a relatively high incidence of this tumour.' Current reports describe a potential risk of mesothelioma in such diverse occupational settings as the non-asbestos textile industry, ${ }^{23}$ the railroad industry, ${ }^{4}$ and building maintenance workers. ${ }^{5}$ In the present report we describe a case of pleural mesothelioma in a patient with a 30 year history of employment as a lift mechanic whose primary exposure to asbestos was from lift brake pads. To our knowledge, this is the first report of mesothelioma occurring in a member of this occupational group.

\section{Case report}

A 56 year old man, in general good health, was noted to have anisocoria on routine physical examination in February 1984 . Chest $x$ ray films were obtained and were within normal limits. Neither the patient nor his wife were aware of the pupillary abnormality and therefore the time of its development was unclear. The patient was referred for a neuro-ophthalmic evaluation which showed a right Horner's syndrome of uncertain aetiology. The medical history included hypertension (controlled on medication) and a hospital admission in 1983 for renal stones. There was also a family history of breast and colon cancer and a 40 pack-year smoking history.

In late April 1984 he was seen in the emergency room of another hospital complaining of right upper quadrant pain and chest discomfort (of about one week's duration) which persisted after returning home with medication. His pain became increasingly severe prompting his return to the hospital emergency room.

Accepted 18 July 1988
He was admitted to hospital on 2 May 1984 for furtheक्ष evaluation.

Gallbladder ultrasound results performed as ar outpatient before admission were normal. Subsequeni sonograms of the upper abdomen showed no abnor mality. A barium enema and intravenous pyelogram? were performed and a probable prostatic enlargement was noted. Gastrointestinal series showed "only $\vec{a}$ mild deformity of the duodenum with no acute disease," and an abdominal CT scan showed only a mild prominence of the head of the pancreas. The patient was discharged home and was schedule for 0 repeat CT scan to include both the upper abdominat area and chest one week later.

The subsequent CT of the chest (on 11 May 1984) showed a right paracervical mass extending to the midclavicular line. The patient was admitted toD hospital on 21 May 1984 for bronchoscopy and right thoractomy with biopsy of the pleura, diaphragm cardiac fat pad, and suprasternal notch. Biopsys specimens were positive for "desmoplastic malignan f fibrous mesothelioma" with extension to the chest wall, diaphragm, and pericardium. He was discharged on 2 June 1984 and began chemotherapy ten days later. In addition, he received radiotherapy to the righ? chest and supraclavicuolar mass. In March 1985 the patient received additional radiotherapy for relief of severe right arm pain secondary to brachial plexus involvement. In April he developed increasing confusion and a CT scan of the head showed evidencep of metastasis to the left frontal area. He subsequentlye. received radiotherapy to the head and was admitted to hospital because of extreme right side and shoulder pain uncontrolled by morphine. In addition, he los the use of his right hand about three weeks before hew was admitted in May 1985. The patient died one week later.

Necropsy showed mesothelioma of the right chesर्ष infiltrating the ribs and thoracic vertabrae. Tumour ${ }^{+}$ was also found at the right lung apex. Metastases were found in the contralateral lung, both adrenal glands, and liver. The left pleura showed no evidence of mesothelioma. Fibrous plaques were present in the 
right pleura (right lower lobe) and pericardium.

Pathology slides of the tumour were reviewed by an expert pathologist at the Canadian Tumor Reference Center and were classified as "desmoplastic diffuse pleural mesothelioma, biphasic." Unfortunately, because of necropsy restrictions, the suspected cerebral metastasis could not be evaluated histologically.

An occupational questionnaire completed after the initial diagnosis of mesothelioma indicated that the patient had been employed for $\mathbf{3 0}$ years as a lift mechanic. His duties during his employment were listed as "helper, mechanic, maintenance and repair, and supervisor of lift installation." His primary exposure to asbestos was to lift brake linings which he routinely cut, fitted, and removed during lift installation and maintenance. No occupational history was available before the age of 26 , although the patients reported exposure to asbestos only during his employment as a lift mechanic.

\section{Discussion}

Mesothelioma is a rare tumour in the general population with an annual age adjusted incidence of $0.9 \mathrm{per}$ 100000 among white men and 0.3 per 100000 among white women in the United States. ${ }^{6}$ Asbestos is the primary aetiological factor in the development of this disease with asbestos exposed occupational cohorts often experiencing substantially raised incidence-for example, an annual incidence of over 200 cases per million for men over age 45 in the shipbuilding industry. ${ }^{7}$

Initially, occupational groups at risk for mesothelioma were limited to asbestos miners, millers, and factory workers. Subsequently, groups such as insulators and pipe fitters using asbestos products were shown to experience a high incidence of this tumour. Currently, reports of mesothelioma associated with domestic, environmental, and "secondary" exposure to asbestos in non-asbestos industries have been published. ${ }^{8-10}$

Two aspects of the pleural mesothelioma in this man are unusual: (1) the possible aetiologal association with an unusual occupational exposure to asbestos and (2) the possible existence of a cerebral metastasis. It is unfortunate that necropsy restrictions did not allow evaluation of a suspected cerebral metastasis shown on a CT scan. Although metastatic spread of pleural mesothelioma is now recognised as a common feature of this disease, " brain metastases are rare. Only 14 documented cases have been reported.

Previous studies have documented measurable concentrations of asbestos fibres in the work environment of individuals engaged in vehicle brake lining repair and installation. ${ }^{1213}$ In addition, several investigators have reported cases of mesothelioma in brake repair workers, suggesting the existence of a risk of mesothelioma among this group. ${ }^{14}$ In the case presented here the patient was exposed to asbestos brake products for 30 years when employed as a lift mechanic. It is also conceivable that he was exposed to asbestos building insulation during lift installation and repair. In the light of previous reports indicating an increased risk of mesothelioma among vehicle brake repair workers, a similar high risk of this tumour among lift brake mechanics appears plausible. Increased surveillance of this occupational group for asbestos related cancers may be justified.

This case was obtained from the files of the Canadian Tumor Reference Center with which one of the authors (MH) was previously affiliated. We thank the Reference Center for providing material for this report. We also thank Barbara Milatou-Huncharek for typing the manuscript.

\section{References}

1 Selikoff IJ, Lee DHK. Asbestos and disease. New York: Academic Press, 1978.

2 Paci E, Dini S, Buiatti E, et al. Malignant mesothelioma in nonasbestos textile workers in Florence. Am J Ind Med 1987;11:249-54.

3 Quinn MM, Kriebel D, Buiatti E, et al. An asbestos hazard in the reprocessed textile industry. Am J Ind Med 1987;11:255-66.

4 Schenker MB, Garschick E, Munoz A, et al. A population based case control study of mesothelioma deaths among US railroad workers. Am Rev Respir Dis 1986;134:461-5.

5 Gronemeyer J, Lilis R, Selikoff IJ. Health status of New York City Board of Education Workers. Findings in examination of 115 workers, September 1984-March 1985. New York: New York City Board of Education, 1986.

6 Schottenfeld D, Fraumeni JF. Cancer epidemiology and prevention. Philadelphia: WB Saunders Co, 1982:576-7.

7 McDonald JC, McDonald AD. Epidemiology of mesothelioma from estimated incidence. Prev Med 1977;6:426-46.

8 Anderson HA, Lilis R, Daum SM, Fishbein AS, Selikoff IJ. Household contact asbestos neoplastic risk. Ann NY Acad Sci 1976;271:311-23.

9 Li FP, Lokich J, Lapey J, Neptune WB, Wilkins EW. Familial mesothelioma after intense asbestos exposure at home. JAMA 1978;240:467.

10 Young I, West S, Jackson J, Cantrell P. Prevalence of asbestos related lung disease among employees in non-asbestos industries. Med J Aust 1981;1:464-7.

11 Huncharek M, Muscat J. Metastases in diffuse pleural mesothelioma: influence of histological type. Thorax 1987;42:897-8.

12 Rohl AN, Langer AM, Wolff MS, Weismann I. Asbestos exposure during brake lining maintenance and repair. Environ Res 1976;12:110-28.

13 Lorimer MV, Rohl AN, Miller A, Nicholson WJ, Selikoff IJ. Asbestos exposure of brake repair workers in the United States. Mt Sinai J Med 1976;43:207-8.

14 Langer AM, McCaughey WTE. Mesothelioma in a brake repair worker. Lancet 1983;ii:1101-3. 